\title{
Calibrating Energy Performance Model of a Hospital Building: Dealing with Practical Issues of Data Availability and Granularity in a Case Study Building in the UK
}

\author{
Nishesh Jain ${ }^{1}$, Esfand Burman ${ }^{1}$, Dejan Mumovic ${ }^{1}$, Michael Davies ${ }^{1}$ \\ ${ }^{1}$ UCL Institute of Environment Design and Engineering, University College London, London, UK
}

\begin{abstract}
Calibration of energy models is mathematically a highlyparameterized and under-determined problem. Hospitals are energy intensive buildings that have complex and varying specifications for their functions and operations. Calibration of energy models of hospitals is further challenging due to difficulties such as base-load estimation and end-use disaggregation of a 24-hour running facility's measured energy use (specially enduses such as specialist equipment and plug loads). This paper attempts to calibrate the energy model of a hospital building in the UK. Along with design stage building construction documentation, on-site observations and semi-structured stakeholder interviews, energy and Indoor Environmental Quality (IEQ) data is collected for a period of one year. A calibrated energy model is then used to quantify the effects of the observed energy performance gap issues found in the building. The energy and IEQ for the building are compared against design stage targets and industry benchmarks. The paper also reflects on practicalities of data collection such as shortcomings in metering, monitoring and observations that could be addressed for model calibration in hospitals.
\end{abstract}

\section{Introduction}

In the non-domestic building sector in the UK, hospitals are one of the most energy consuming buildings and have a significant energy performance gap (CarbonBuzz, 2019). Hospitals are complex buildings that are occupied $24 / 7$ by many people. As many of these people are vulnerable and have specialist medical needs, there is a need for a strict control over IEQ, especially, thermal comfort and Indoor Air Quality (IAQ) as they are the most crucial IEQ components in an hospital context.

Owing to the critical function a hospital has, the primary focus for building managers is to ensure reliable running of building and building services and the compliance with strict health and safety and other clinical requirements (DH, 2015). Specialist medical equipment, sterilisation, laundries and food preparation not only increase energy use but are very difficult to monitor and manage with regards to energy performance (Ziębik \& Hoinka, 2013). Using of calibrated energy simulation models to identify and validate performance gap issues and quantify benefits resulting from Energy Efficient Measures (EEMs) is common practice (Jain, et al., 2018). This is also recommended for hospital buildings in HTM 07-02-
$\mathrm{EnCO}_{2} \mathrm{de}(\mathrm{DH}, 2015) . \mathrm{EnCO}_{2} \mathrm{de}$ provides guidance on managing responsible energy use within the health sector. However, the type of specialist needs and unique loads present in hospitals, along with irregular operational demand brings in high degree of uncertainty in modelling real performance, thereby making accurate model calibration a challenging exercise.

The complexities of energy systems and operational considerations mean that, amongst the main non-domestic buildings, hospitals have not been the focus of detailed energy analysis and performance gap studies, even lesser so as a subject of energy model calibration exercises.

This paper, reports on a hospital building, which is a newly constructed extension to an existing campus. It deals with the challenges of calibrating an energy model and highlights the key energy and IEQ performance issues in hospital buildings. The main objectives of the work are:

1. To compare the design stage estimates with the actual performance for establishing the performance gap and map them against wider industry benchmarks.

2. To analyse the IEQ performance relating to thermal comfort and IAQ and report any performance issues.

3. To identify and validate root causes of the gap and issues identified based on on-site observations, interviews and using energy simulation models.

4. To determine and address key challenges with regards to practicalities of data collection and data availability in creating and validating the calibrated model.

The paper first provides a background regarding performance objectives, benchmarks and performance gap issues in hospitals in relation to energy and IEQ. It also discusses the uses and challenges of calibrating hospital energy simulation models. Then, the case study building's performance is analysed, performance gap and its causes are identified, and a calibrated energy model created. The paper concludes with lessons regarding challenges faced in calibration and model validation, along with reflections on the overall performance, performance gap and its underlying root causes.

\section{Background}

\section{Performance objectives in hospital buildings}

Hospitals are 24/7 running buildings having specialist energy intensive equipment used and processes followed for their regular operations, and to ensure that strict requirements with regards to IEQ are met. This results in 
energy use intensity in hospitals to be one of the highest among non-domestic buildings, (Hong \& Steadman, 2013). Yet, unlike critical issues of thermal comfort and IAQ, the academic research regarding the energy use in hospitals and data for major hospital end uses, such as cooling, heating, lighting, and plug loads, is sparse (Sheppy, et al., 2014).

However, recent climate change legislations, such as, Energy Performance of Buildings Directive (EPBD) in Europe, and rising energy costs have driven policies to focus on sector wise targets, making hospital energy use reduction as one of the objectives. Driven by these, guidance documents on energy efficient hospitals (DH, 2015) are widely available, but actual energy use reporting and corresponding robust benchmarking is not. Benchmarking of energy use for hospitals in general is difficult because of heterogeneous mix of buildings that fall in this sector owing to the complexity and the differing set-ups of each hospital. A typical hospital definition is very difficult to ascertain.

In the UK, attempts have been made to benchmark energy use in hospital buildings. ECG72 (BRECSU, 1996) and CIBSE TM46 ${ }^{1}$ (CIBSE, 2008) provide typical and good practice benchmarks for electricity and fossil-thermal energy use based on sample data and engineering judgement. Besides this actual energy use of building stock is also available by the energy consumption figures provided through the mandatory UK Department of Health's ERIC ${ }^{2}$ data (NHS Digital, 2018) and also through analysis of $\mathrm{DEC}^{3}$ data presented in Hong \& Steadman (2013). However, information on different energy end-uses, important for the identification of how building performance improvements could be achieved (Burman, et al., 2014) remain very rare. Morgenstern, et al. (2016) analysed 10 studies which explored relevance of different energy end-uses in hospitals. Their findings suggest that, in hospitals, energy demand is dominated by space heating and hot water consumption. For electricity, about two thirds of it is used for lighting, plug loads such as IT or medical equipment or through food preparation. The remaining electricity use is accounted for by the provision of building services, cooling, ventilation, compressed gases and elevators. Maintaining satisfactory IEQ, that is more stringent than that in other building types, is partly responsible for energy use in hospitals to be higher when compared with other buildings.

The strict IEQ performance consideration in hospitals are determined by the activities and special functions the specific area is addressed for. Suitable HVAC systems are necessary to guarantee a careful control of hospitals internal climate, especially with regards to thermal comfort and IAQ. In the UK, BSEN 15251:2007 (BSI, 2007) recommends environmental input parameters for indoor air quality, thermal environment, lighting and acoustics. Additionally, HTM 03-01 (DH, 2007) gives

${ }^{1}$ TM46 provides energy use benchmarks for all building types. Based on UK buildings data, it is used in operational performance comparisons.

${ }^{2}$ Estates Return Information Collection (ERIC) data contains energy consumption figures and site characteristics for all of NHS premises. comprehensive advice and guidance regarding specialised ventilation requirements in healthcare buildings.

\section{Performance gap issues in hospitals}

Hospital building stock in the UK (NHS sites) is constructed over period of up to 100 years. Because of a complex arrangement of building and services that have evolved over time, many having central plants, it is difficult to monitor the energy use of the buildings and departments individually and thereby analyse energy related performance gap and performance issues.

There is a little documentation available for actual energy consumption of various types of hospital buildings. CarbonBuzz ${ }^{4}$ platform provides design and actual energy use data for several hospitals across the UK. The platform, based on a small sample of data, reports significant increase in operational $\mathrm{CO}_{2}$ emissions compared to design estimations for hospital buildings. The median operational $\mathrm{CO}_{2}$ emissions of actual buildings is also a third more than CIBSE TM46 benchmark.

While this provides evidence for energy performance gap, much of the design stage data provided are based on Building Regulations compliance or Energy Performance Certificate calculations. This demonstrates the prevalence of interchangeable and contentious use of the outcomes of Building Regulations compliance calculations as design predictions for buildings (Burman, et al., 2012).

Mechanical systems and their controls in hospitals are designed so that there is a comfortable and healthy indoor environment, as per the strict IEQ requirements. Poor maintenance and traffic related external pollutants, such as $\mathrm{NO}_{2}$, if not managed, could cause underperformance issues for IEQ (Giuli, et al., 2013). Use of $\mathrm{CO}_{2}$ levels as the only determinant for regulating fresh air is insufficient as external pollutants and some internal contaminants could exceed limits and might pose occupant health risks (Fifield, 2016). Moreover, in the context of climate change there is a need for buildings and services to be designed in a way that they are able to maintain good IEQ in the event of extreme weather scenarios, e.g. severe heat and heatwaves (PHE, 2018).

\section{Data monitoring and model calibration challenges for hospital buildings}

A calibrated energy simulation model can be used for various purposes like EEM evaluation, optimisation of building system controls and identification of underlying performance gap issues. However, minimum level of data needed to have reliable results for any calibration exercise is operational energy use for all fuels, obtained from metering strategy or utility data, for a period of at least one year. More detailed monitored data including disaggregated energy use can further improve the calibration accuracy and confidence. This information can be taken from audits (walkthrough and detailed) and short term and long-term disaggregated end use monitored 
energy data (Reddy \& Maor, 2006). Detailed energy use data can be used to create detailed profiles of energy simulation output results and increase confidence in accuracy. However, data quality issues sometimes require statistical post processing to create these profiles. Also, monitoring of some IEQ data streams can provide evidence for detailed building operational profiles. Temperature data can provide evidence of set point temperature being maintained in the spaces. Similarly, $\mathrm{CO}_{2}$ and $\mathrm{PM}_{2.5}$ concentrations can provide details about occupancy patters, ventilation and infiltration rates (Kapalo, 2013), (Parsons, 2014), (Batterman, 2017).

Hospitals, due to the nature of their function, pose many challenges in operational data collection and affect the calibration process. Some of these challenges are:

1. Despite being run $24 / 7$, the irregular nature of processes makes it difficult to describe typical events and average durations of use for various functions.

2. The transient nature of occupancy (patients and some of the changing staff) result in limited knowledge of local customs, that could be collected in site-visits.

3. Different parts of the facility have differing energy intensities of clinical processes and specialist medical equipment and of building service requirements. Detailed audit is difficult due to access restrictions.

4. Hospitals continuously evolve to meet its changing needs. This may result in changes to space use, equipment inventory or building services which might not get updated in the facility managers' records.

5. Controls for IEQ are typically decentralised, by having overrides to modulate local temperature and sometimes air flow rates. This, coupled with transient nature of the occupants, can lead to differing space conditioning in various parts of the building.

Considering these uncertainties, it is difficult to deterministically estimate the simulation input parameters and be certain about the accuracy of the calibration model. A probabilistic approach, similar to the one used by Jain, et al. (2018) is more suitable to represent these calibration results. The observed uncertainties in inputs can be factored in using probable upper and lower values for the inputs to create a best- and worst-case monthly energy use range of calibrated simulation model. The calibration accuracy, then can be increased using evidence-based methods to reduce the variability of the inputs.

\section{Methodology}

The paper assesses the energy and IEQ performance issues and practicality of calibrating energy simulation model of a hospital building in the UK.

1. First, the building's actual performance was assessed by analysing the monitored data for energy, IAQ and thermal comfort ${ }^{5}$. These were also compared against design estimates and industry benchmarks.

2. Subsequently, based on information from design and construction documents, building performance

\footnotetext{
${ }^{5}$ Within IEQ, only IAQ and thermal comfort were assessed as these were being monitored as a part of a larger study across building sector. More parameters could be studied for explicit detailed hospital IEQ analysis.
}

evaluations, regular measurements, observations and semi-structured stakeholder interviews with the facility managers at monthly or bimonthly intervals over a period of one year, reasons for any identified performance gap were explored.

3. A calibrated energy model for monthly energy use was created, using the post-occupancy data along with IEQ (temperature, lighting and $\mathrm{CO}_{2}$ ) data from typical zones. The simulation model was calibrated by evidence-based fine-tuning of building operational inputs, like the process used by Bertagnolio (2012).

4. The calibration model was validated using ASHRAE Guideline 14 / IPMVP protocol. However, to account for various uncertainties in the building operations, a probabilistic approach was also used for its validation.

5. Building level and industry level lessons with regards to energy and IEQ performance and model calibration of hospital buildings are explored.

\section{Case study building}

The case study is an acute ${ }^{6}$ hospital building in Bristol area in South-West England. The nine-floor building is a new ward block within an existing campus with a useful floor area of $\sim 14700 \mathrm{~m}^{2}$. Typical spaces include wards, consulting rooms, offices, diagnostics, operating theatres, a canteen and the usual building amenity rooms.

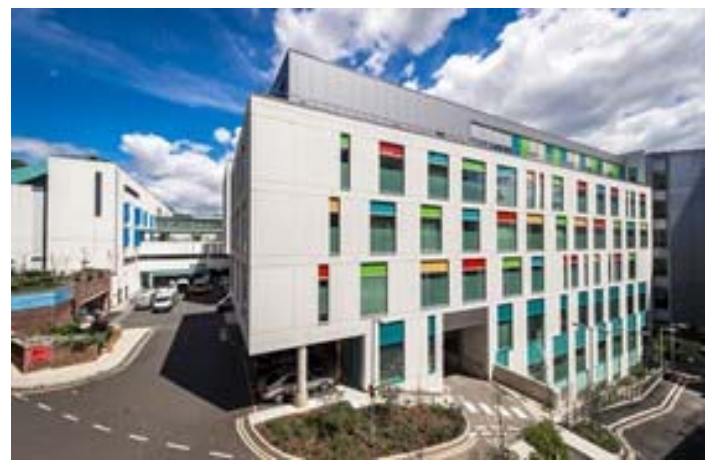

Figure 1: Case study hospital building

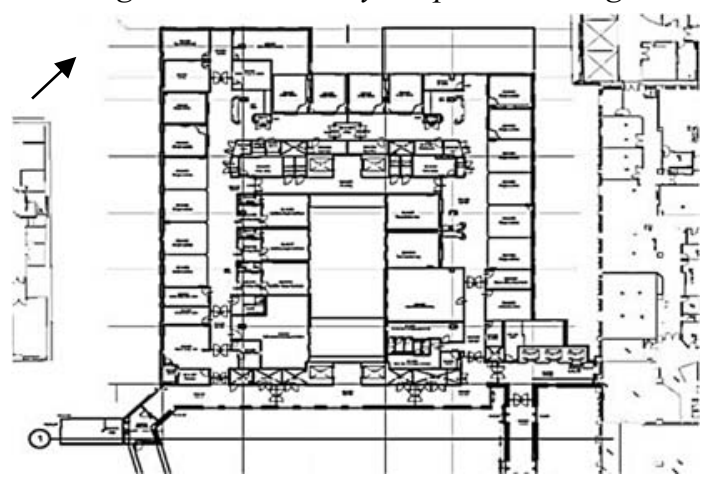

Figure 2: Typical floor plan ( $6^{\text {th }}$ floor)

The building is of curtain wall construction with concrete lattice floor slabs. It is highly insulated and is heavy weight in terms of thermal mass. The building has a $23 \%$ window to wall ratio and has solar control glass. There is no external shading besides the surrounding buildings.

${ }^{6}$ Acute hospitals: As defined in ECG72 (BRECSU, 1996), most National Health Service (NHS) trusts are in this group; or, Hospital (clinical and research): As defined in CIBSE TM46 (CIBSE, 2008) category. 
Most of the building spaces are occupied 24/7 apart from consulting rooms and offices, which are occupied on weekdays from 8 am to $6 \mathrm{pm}$. Details about occupancy were obtained from the occupants, however irregular nature of processes made it difficult for staff to describe typical events and average patterns with high certainty.

Most of the building is heated and cooled using an all air, supply / extract ventilation system with ventilation terminal heating coils. The heat in the building is provided by a low efficiency $(\sim 70 \%)$ old campus wide steam-based central heating network. Mechanical ventilation (MV) with heat recovery and cooling is provided through rooftop mounted air handling units and chillers. The MV system (along with heating and cooling) is controlled via Building Management System (BMS), however individual spaces have analog manual override controls.

Gas use in the facility is metered at site level. But each building has its own heat meter which provides building wise heat demand. The local (building level) electricity meter, accessed via BMS, records hourly electricity use. Disaggregated energy use for lights, small power, IT, pumps and fans and cooling is also available

As per the design stage documents, details about the building fabric, technical parameters and operational parameters of building services are listed in the Table 1.

Table 1: Building fabric, operations and load details

\begin{tabular}{|l|l|}
\hline Fabric Element & Details \\
\hline Walls & U-Value $=0.22 \mathrm{~W} / \mathrm{m}^{2} \mathrm{~K}$ \\
\hline Windows & U-Value $=1.60 \mathrm{~W} / \mathrm{m}^{2} \mathrm{~K}$ (incl. frame effect) \\
\hline Floors & G value $=0.43, \mathrm{VLT}=0.70$ \\
\hline Roofs & U-Value $=0.25 \mathrm{~W} / \mathrm{m}^{2} \mathrm{~K}$ \\
\hline Airtightness & U-Value $=0.23 \mathrm{~W} / \mathrm{m}^{2} \mathrm{~K}$ \\
\hline End Use & $5 \mathrm{~m}^{3} / \mathrm{hr} / \mathrm{m}^{2} @ 50 \mathrm{~Pa}$ \\
\hline Heating & Details \\
\hline Cooling & Set point: $22^{\circ} \mathrm{C}$ \\
\hline & Set point: $24^{\circ} \mathrm{C}$ \\
\hline Mech. Vent. with & Wards: $17.41 / \mathrm{s} /$ person \\
Heat Recovery & Food areas $/$ kitchens: $25 \mathrm{l} / \mathrm{s} /$ person \\
(HR) & Operation theatres: $1291 / \mathrm{s} /$ person \\
& Other spaces: 10 to $12 \mathrm{l} / \mathrm{s} /$ person \\
\hline Int. Lighting load & SPF: $1.7 \mathrm{~W} / \mathrm{l} / \mathrm{s} ; \mathrm{HR}$ eff: 0.75 \\
\hline Auxiliaries & $2.7 \mathrm{~W} / \mathrm{m}^{2}$ in wards but varies as per space \\
\hline Small Power load & $12.5 \mathrm{~W} / \mathrm{m}^{2}$ in wards but varies as per space \\
\hline
\end{tabular}

\section{Building Performance}

\section{Design stage and operational energy performance}

The design stage projection of energy performance was done as a part of Part L Building regulations compliance documentation and for $\mathrm{EnCO}_{2}$ de requirements. Design stage projections were also recalculated as per CIBSE TM54. Figure 3 compares projected Part L, EnCO $\mathrm{E}_{2} \mathrm{de}$ and CIBSE TM54 results with actual energy use and ECG72 good practice benchmark. The disaggregated electricity use of the building was available from the BMS, whereas, heat demand was recorded from a physical heat meter.

There is a significant underestimation of energy use in the design stage Part L calculations. The major reason for it

${ }^{7}$ National Calculation Methodology (NCM), used in the UK to facilitate the Building Regulations compliance calculations specify standardised is that these calculations, primarily aimed at benchmarking, exclude key energy use areas such as plugin equipment in the total projections. Moreover, the occupancy and operational profiles are calculated based on $\mathrm{UK} \mathrm{NCM}^{7}$ defaults which, in real scenarios, can be significantly different. The methodology proposed in CIBSE TM54 and $\mathrm{EnCO}_{2}$ de provides an approach for estimating operational energy use at the design stage, accounting for all end uses in the building alongside realistic operating patterns and behaviours.

The energy use of various end-uses in these projections differs from actual use. They underestimate the heating energy use and overestimate the equipment usage. These variations however can be easily attributed to epistemic uncertainties in setpoint temperatures and operations of hospital equipment. At design stage, to account for variations in design and operation of the building, CIBSE TM54 recommends developing scenarios based on estimated input variability to inform the designers about realistic best, worst and most likely energy use patterns.

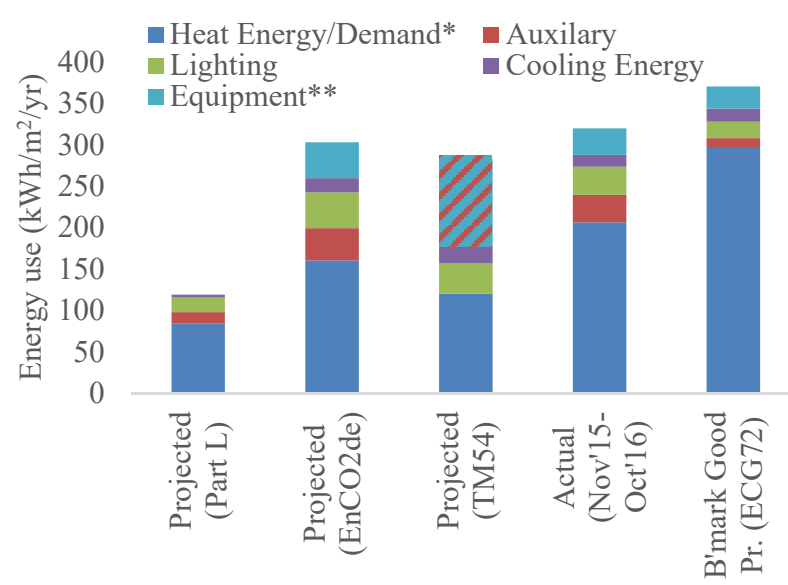

*Heat demand (incl. DHW) instead of heating energy except for projected Part-L values; **Equipment (small power, IT and misc. loads) in TM54 graph includes auxiliaries as well.

Figure 3: Comparison of projected (Part L), projected (EnCO $\mathrm{C}_{2} \mathrm{de}$ ), projected (TM54) \& actual energy use

Additionally, Part L under-estimation of fossil-thermal energy was due to the low efficiency of the steam-based central heating network. A new, efficient, combined heat and power (CHP) plant was used in calculations instead of the existing network, which was conditionally allowed. The new CHP plant was to be installed following a major renovation to maximise the efficiency savings across the facility rather than as a separate system for the new building only. As this has not happened yet the present thermal performance of the building is much worse than expected from a new building. Table 2 compares the building's performance with similar UK buildings and benchmarks. Compared with other similar buildings, this building's energy use is $26 \%$ less than the median (Hong $\&$ Steadman, 2013). It is in the top $30 \%$ of such buildings.

operating conditions for comparing various buildings against a reference building. 
Table 2: Comparison with benchmarks

\begin{tabular}{|c|c|c|c|}
\hline Criteria & $\begin{array}{c}\text { Energy Use } \\
(\text { Gas + Elec) } \\
\left(\mathbf{k W h} / \mathbf{m}^{2}\right)\end{array}$ & $\begin{array}{c}\mathrm{CO}_{2} \\
\text { emission } \\
\left(\mathrm{kgCO}_{2} / \mathrm{m}^{2}\right)\end{array}$ & $\begin{array}{c}\text { Diff from } \\
\text { benchmark }\end{array}$ \\
\hline Current Performance & $318(206+112)$ & 99 & - \\
\hline CIBSE TM46 ${ }^{8}$ & $510(420+90)$ & 130 & $24 \%$ Less \\
\hline ECG72 Best Practice ${ }^{9}$ & $498(423+75)$ & 122 & $19 \%$ Less \\
\hline $\begin{array}{l}\text { Similar UK } \\
\text { hospitals }^{10}\end{array}$ & $429(311+118)$ & 123 & $19 \%$ Less \\
\hline
\end{tabular}

Comparing the disaggregated electricity use, medical equipment energy, unique to the hospitals, uses a sizeable proportion $(\sim 30 \%)$ of this hospital's electricity. Lighting and auxiliaries consume about $30 \%$ each and remaining ( $\sim 10 \%)$ is being used for provision of cooling.

\section{Building IEQ performance}

The hospital's IEQ performance issues are significantly lower due to the close control that facility manages must maintain over indoor environment, in order to meet the strict IEQ requirements of a hospital. To assess the thermal comfort and IAQ, monitoring was done for some patient wards. The parameters recorded and reported in this paper are temperature, $\mathrm{CO}_{2}$ (a proxy for air change rate) $\mathrm{PM}_{2.5}$ levels and $\mathrm{NO}_{2}$ (predominantly driven by traffic). Results for heating and non-heating months along with typical weeks are presented.
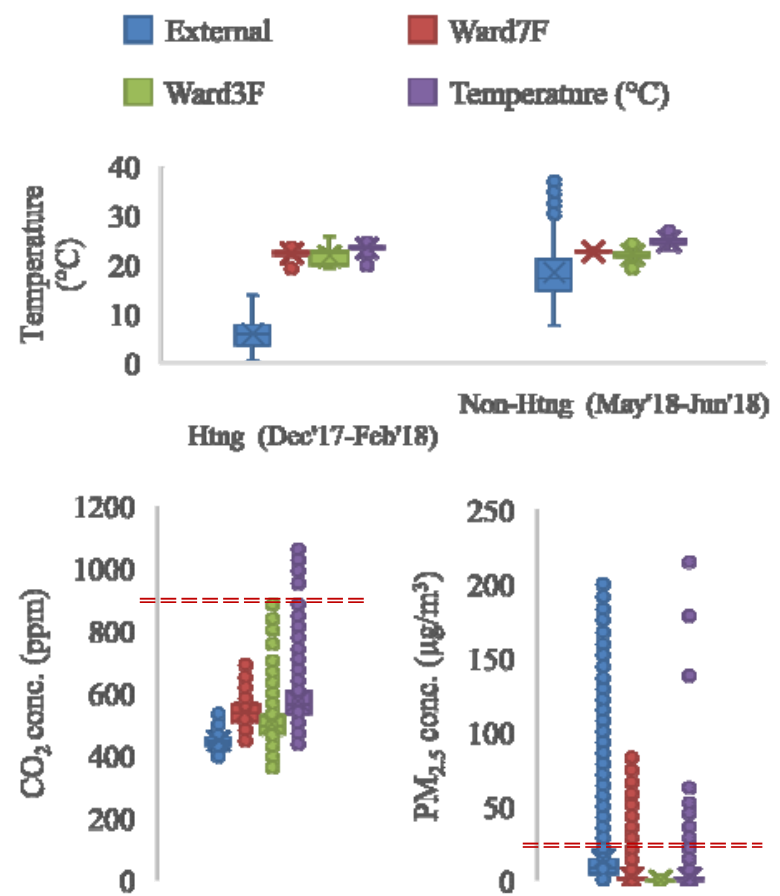

$====$ WHO recommended guidelines

$\mathrm{CO}_{2}:$ Ext +550 ppm; $\mathrm{PM}_{2.5}: 24$-hour avg of $25 \mu \mathrm{g} / \mathrm{m}^{3}$

Figure 4: Temp., $\mathrm{CO}_{2}$ and $\mathrm{PM}_{2.5}$ measurements in some wards (Box and whisker plots-Inter Quartile Range)

Figure 4 shows the spread of temperature, $\mathrm{CO}_{2}$ and $\mathrm{PM}_{2.5}$ levels for the three patient wards on floors 3, 4 and 7 . These were measured for summer and winter months in

${ }^{8}$ Benchmark for acute hospitals (CIBSE, 2008)

${ }^{9}$ (BRECSU, 1996)
2017-18. Generally, the temperatures were between 20$24^{\circ} \mathrm{C}$ and were about $1-2^{\circ} \mathrm{C}$ higher in summers than in winters. This is in line with spot and typical week measurements done during energy use monitoring period of 2015-16. $\mathrm{CO}_{2}$ levels in all monitored wards remained below $950 \mathrm{ppm}$ due to effective MV and high air change rates. This is in accordance with class 1 requirement ${ }^{11}$ as per in BS EN 16798. To meet these requirements. MV system provides 10 ach to most medical spaces and 6 ach to examination and measurement rooms. $\mathrm{PM}_{2.5}$ levels were also significantly lower than external levels and were less than the WHO 24-hour mean threshold of 25 $\mu \mathrm{g} / \mathrm{m}^{3}$ (WHO, 2005). This shows that the MV air filters effectively controlled the ingress of micro particles.

It should be noted that maintaining high IEQ through high air changes and filtration comes at an energy expense. Consequently, fans and pumps used to provide this close control use around $30 \%$ of total electricity (see Figure 3 ).

A key finding in this building, located in a congested urban area, was the lack of measures against ambient $\mathrm{NO}_{2}$. Indoor $\mathrm{NO}_{2}$ levels recorded in the hospital wards very closely followed the external levels (Figure 5). These recordings often went above the WHO annual mean threshold of $40 \mu \mathrm{g} / \mathrm{m}^{3}$. This suggests a potential risk of exposure id external air remains polluted for prolonged periods. Therefore, holistic air filtration measures such as carbon filters in addition to particle filters are needed.

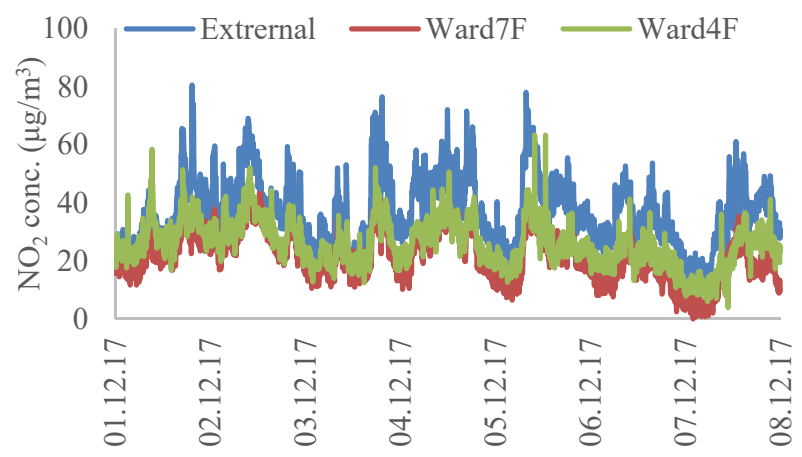

Figure 5: $\mathrm{NO}_{2}$ concentrations in hospital spaces (Dec)

\section{Model Calibration and Validation}

To understand the performance of the hospital in detail, a calibrated model was created in DesignBuilder Software (an interface to EnergyPlus). The monthly calibration was validated as per ASHRAE Guideline 14 criteria of CV(RMSE) $<15 \%$ and NMBE $< \pm 5 \%$ (ASHRAE, 2014).

\section{Building's monthly operational energy performance}

Obtaining disaggregated, regular and high granularity data for any building can be a very challenging task. While logistics of extensive monitoring is always a factor, in hospitals, practical issues during sites visit such as access, regularity and data quality are also encountered. For this hospital, hourly disaggregated electricity use data was available from BMS system. However, as central steam network was used for heating and hot water, only monthly spot measurement of the heat-meter readings

\footnotetext{
${ }^{10}$ Median value as per DEC rating records (Hong \& Steadman, 2013)

${ }^{11}$ Class 1 typical range: $\leq 550$ ppm above outdoor (BSI, 2015)
} 
were available. Figure 6 shows building's monthly electricity use and heat demand profile. It can be noted that there is a significant heating energy demand during the non-heating periods (Jun-Sep). This base heat demand is primarily for hot water use, which in hospitals in the UK has been reported to constitute a significant proration of total energy use (DECC, 2018 ). It was not possible to monitor disaggregated heat demand for heating and hot water. However, as hot water demand in hospitals is largely independent of external weather conditions, the approximate baseline demand for it can be calculated using Heating Degree Days (HDD). Figure 7 plots the heat demand against HDD. Intercept of the best fit line provides the approximate monthly hot water heat demand.

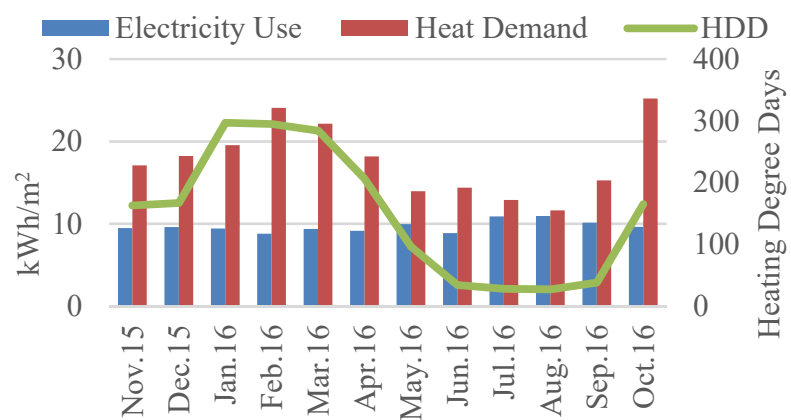

Figure 6: Building's monthly electricity use and heat demand (Nov-15 to Oct-16)

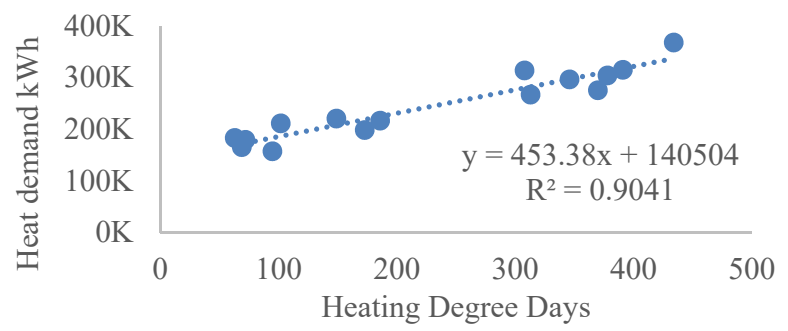

Figure 7: HDD analysis to estimate non-heating part of monthly gas demand (Data used from 2015 to 2016)

\section{Model calibration}

For simulation model calibration, information regarding some of the inputs were known more precisely than others. While the building fabric and occupancy profiles of a 24/7 use were certain, data for inputs such as exact operational trends of various spaces, their equipment loads and equipment operation, set-point temperatures had high degree of uncertainty. The uncertainty in these inputs arose because of the irregular nature of processes in hospitals, making it difficult to identify typical events and average durations of use. The transient nature of occupants and their needs further added to this uncertainty. To develop the calibrated model, best estimated values for inputs were used which were based on on-site spot observations, use of secondary data trends and information from facility managers. For the information that was readily available, all finetuning was done based on evidence gathered. However, for the inputs with high uncertainty manual finetuning was done after the point where enough evidence-based data was not available. The overall calibration process is the same define in Table 3 lists various settings used in the calibrated model and Figures 8 and 9 show calibrated heat demand and electricity use respectively. The calibrated model had a CV(RMSE)/NMBE of 6.6/-2.3 for heat demand and 6.4/-5.0 for electricity use respectively.

Table 3: Calibration model settings

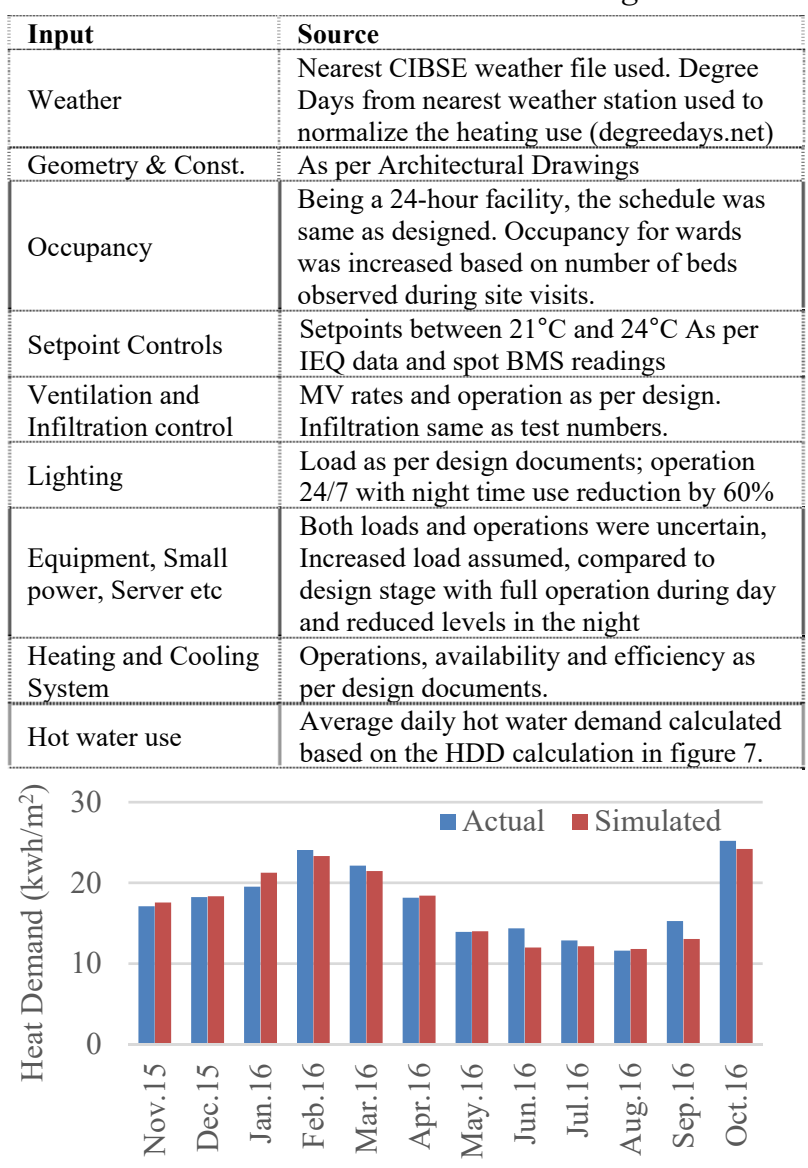

Figure 8: Simulated vs actual monthly heat demand

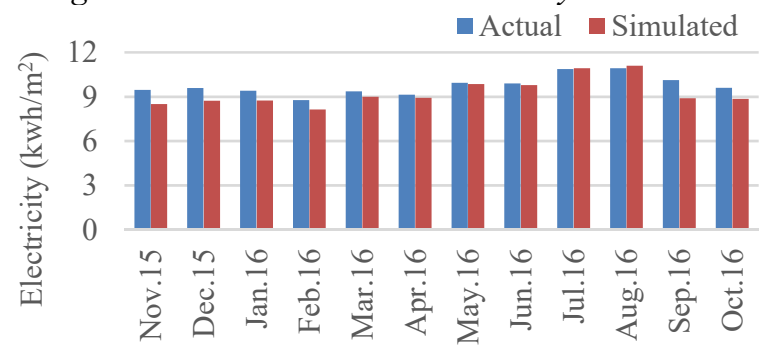

Figure 9: Simulated vs actual monthly electricity use

\section{Probabilistic representation of calibration results}

For the uncertain input parameters, use of best estimated values for creating a calibrated model in lieu of directly and regularly monitored data, can provide misleading conclusions. Even though calibration criteria were met, there is a need for presenting upper and lower range of monthly energy use scenario that capture the underlying uncertainty. Therefore, for each of the uncertain inputs, instead of a best estimated value, a probable range needs to be defined. Some major uncertain inputs and their impacts in this case study are described and shown below.

Setpoint temperatures: The design stage data, as per UK $\mathrm{NCM}$ guidelines used $22^{\circ} \mathrm{C}$ and $24^{\circ} \mathrm{C}$ as heating and cooling setpoints for wards throughout the year. However, 
it was observed in IEQ data for sample rooms that actual temperatures maintained were around $19-21^{\circ} \mathrm{C}$ in heating season and $22-23^{\circ} \mathrm{C}$ in non-heating season. Spot measurements done on the BMS system which observes all the spaces showed that room setpoints were anywhere from $18^{\circ} \mathrm{C}$ to $24^{\circ} \mathrm{C}$ depending on local requirements.

Hot-water requirement: Hospital hot water energy use is reported to vary widely, ranging from $10 \%$ of heating energy to up to $35-40 \%$. The actual daily demand in the hospital was 4 times the UK NCM assumption of $3.41 / \mathrm{m}^{2}$.

Equipment load and operation: This is one of the most uncertain areas for energy use estimation in hospitals. Depending on the type of the department these loads can vary a lot. For example, for consulting areas field studies have shown the loads to be between $3-7 \mathrm{~W} / \mathrm{m}^{2}$ (Sheppy, et al., 2014) whereas UK NCM uses $27.31 \mathrm{~W} / \mathrm{m}^{2}$. Table 4 lists the uncertainty ranges and Figure 10 and 11 show the simulation results with that uncertainty.

Table 4: Deviation areas and its ranges

\begin{tabular}{|l|l|}
\hline Input area & Range \\
\hline Heating set point temperature & $20^{\circ} \mathrm{C}$ to $23^{\circ} \mathrm{C}$ \\
\hline Cooling setpoint temperature & $21^{\circ} \mathrm{C}$ to $24^{\circ} \mathrm{C}$ \\
\hline Hot water demand & $51 / \mathrm{m}^{2} /$ day to $151 / \mathrm{m}^{2} /$ day \\
\hline Equipment load & 5 to $20 \mathrm{~W} / \mathrm{m}^{2}$ \\
\hline
\end{tabular}

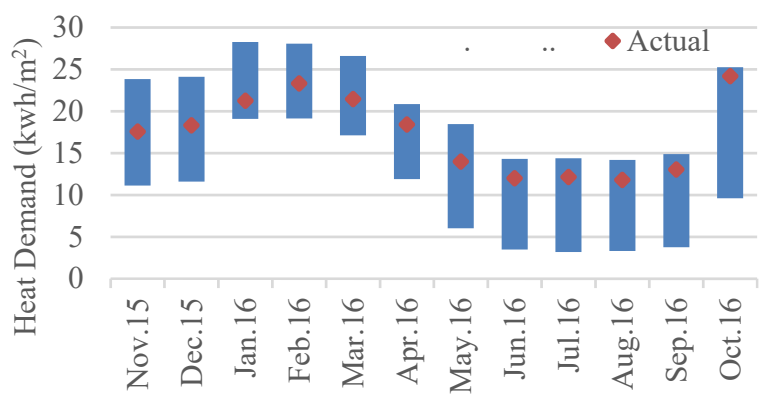

Figure 10: Probabilistic vs actual monthly heat demand

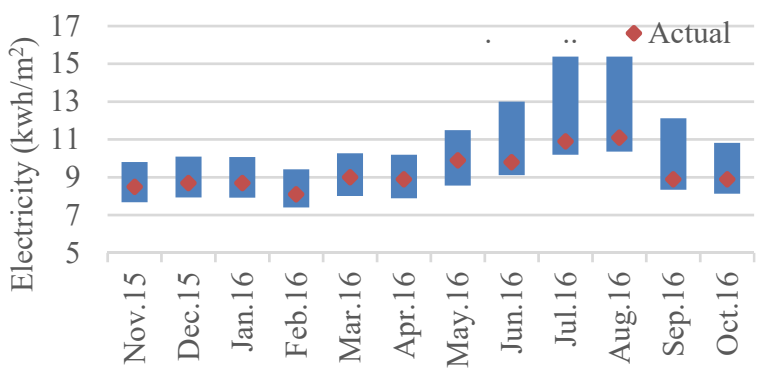

Figure 11: Probabilistic vs actual monthly electricity use

The bars indicate the maximum and minimum range in which monthly energy use would lie in due to the variability in the input. The actual energy use in that month is marked by the dot. This diagram suggests that the actual value of these inputs lie somewhere in between. More monitoring evidence is required to further narrow down these ranges. Additionally, use of probabilistic deviation of these input parameter along with sensitivity analysis that factors in even more parameters could also be used, however, this is out of the scope of this study.

\section{Discussion and Conclusion}

This hospital's energy consumption is within the typical benchmarks, however estimating hospital operations for benchmarking, design stage calculations or creating a calibrated model is challenging. Also, the thermal comfort and most IAQ parameters are within acceptable levels, however, there were some issues with filtration systems used for traffic related pollutants. In this section, we look at these factors in a larger context.

Design projections of energy performance: Design stage calculation need to account for realistically expected operating conditions. Hospital's design stage operational energy use should be calculated as per CIBSE TM54 or $\mathrm{EnCO}_{2} \mathrm{de}$, accounting for all end uses in the building alongside realistic operating patterns and behaviours. Use of Building Regulation compliance is not appropriate as it generally leads to significant underestimation.

Managing speciality nature of hospital: Different clinical processes have different energy demands and services requirements. As it is difficult to generalise a hospital's function, its energy analysis and benchmarking needs to look beyond entire buildings and consider departments or other sub-spaces as unit of analysis.

Safeguards for energy efficient technology: The inept steam-based heating network is still being used in the hospital due to the budgetary constraints of the NHS. To minimise the long-term impact of inefficient systems, robust regulatory safeguards are needed to ensure that the proposed low or zero carbon strategies and technologies will be used in practice, within acceptable timelines.

Challenges in calibration of a hospital model: Use of disaggregated end use metering, IEQ data trends, design documentation, site observations and semi-structured stakeholder interviews were effective for calibration of this model. However, detailed operation stage analysis of energy use trends and patterns of various parts of this 24/7 facility are vital for a validated calibrated model. Some of the unique challenges in hospital model calibration are:

1. Specialist, non-standardised and irregular nature of functions and processes makes it difficult to define typical demands, usage profiles and schedules.

2. Detailed audit of installed equipment and other loads is difficult due to access restrictions.

3. As hospitals dynamically evolve to meet the changing needs there is a high probability of undocumented changes to space use.

4. Controls for indoor environment (such as temperature) are typically decentralised with manual overrides, making their estimation very uncertain.

5. Hospitals can have some services at facility level such as central plants for heating and on the other hand some can be recorded locally at building level such as electricity use. This makes disaggregation and demand assessment at building level complicated.

Validation of calibrated models: Deterministic statistical criteria (ASHARE Guideline 14) do not acknowledge uncertainty in model inputs. As there are multiple solutions may exist that can meet the criteria, conclusions drawn from that for actual operations might be incorrect. A probabilistic approach, while not necessarily improving on calibration accuracy, when used along with existing protocols, provides a way to determine the confidence levels in the calibrated model. 
The case for holistic performance: To deliver a high level of overall performance, IEQ needs to be addressed simultaneously with energy. Hospital MV systems give the necessary controls for maintaining high IAQ. Besides $\mathrm{CO}_{2}$ concentrations-based controls, filtration is used provide a level of protection against outdoor sources of pollution such as microparticles. However, some trafficrelated pollutants such as $\mathrm{NO}_{2}$ are not mechanically filtered and advanced activated carbon filters or other measures are required to enact chemical filtration.

\section{Acknowledgement}

We gratefully acknowledge the financial support by UCL Overseas Research Scholarships (UCL-ORS), DesignBuilder Software Ltd. and The 'Total Performance' of Low Carbon Buildings in China and the UK ('TOP') project funded by EPSRC (EP/N009703/1).

\section{References}

ASHRAE, 2014. Guideline 14, for Measurement of Energy and Demand Savings, Atlanta: American Society of Heating, Refrigerating and Air-Conditioning Engineers

Batterman, S., 2017. Review and Extension of CO2Based Methods to Determine Ventilation Rates with Application to School Classrooms. International Journal of Env. Research and Public Health, 14(2), p. 145.

BRECSU, 1996. Energy consumption guide 72: Energy consumption in hospitals, Watford, UK: Building Research Energy Conservation Support Unit (BRECSU).

Bertagnolio, S., 2012. Evidence-based model calibration for efficient building energy services. Ph.D. Thesis, Liège, Belgium: University of Liège.

BSI, 2007. Indoor env. input parameters for design and assessment of energy performance of buildings addressing IAQ, thermal environment, lighting and acoustics, London: British Standards Institution.

BSI, 2015. BS EN 16798-1. Energy performance of buildings. Part 1. Indoor environmental input parameters for design and assessment of energy performance of buildings addressing indoor air quality, thermal environment, lighting and acoustics. Module M1-6, London: The British Standards Institution.

Burman, E. et al., 2014. A comparative study of benchmarking approaches for non-domestic buildings: Part 2 - Bottom-up approach. International Journal of Sustainable Built Environment, 3(2), pp. 247-261.

Burman, E., Rigamonti, D., Kimpain, J. \& Mumovic, D., 2012. Performance gap and thermal modelling: a comparison of simulation results and actual energy performance for an academy in North-West England. Loughborough, First BSO Conference.

CarbonBuzz, 2019. CarbonBuzz Sector:Health. [Online] Available at:

https://www.carbonbuzz.org/sectorbreakdown.jsp?id=4

CIBSE, 2008. TM 46: Energy benchmarks, London, UK: Chartered Institute of Building Services Engineers.
DECC, 2018 . Energy Consumption in the UK (2018) Chapter 5: Service sector energy consumption in the UK between 1970 and 2017, London, UK: Department of Energy \& Climate Change, UK.

DH, 2007. Health Technical Memorandum 03-01: Specialised ventilation for healthcare premises, London: Department of Health, UK.

DH, 2015. Health Technical Memorandum 0702:EnCO2de 2015 - making energy work in healthcare, London: Department of Health and Social Care.

Fifield, L.-J., 2016. Monitoring UK hospital building type performance: $\quad P h D$ Thesis, Loughborough: Loughborough University.

Giuli, V. D. et al., 2013. Measured and perceived indoor environmental quality: Padua Hospital case study. Building and Environment, Volume 59, pp. 211-226.

Hong, S.-M. \& Steadman, P., 2013. An Analysis of Display Energy Certificated for Public Buildings, 20082012, London, UK: Chartered Institution of Building Services Engineers (CIBSE).

Jain, N. et al., 2018. Comparative Analysis of Protocols Used in Measurement and Verification of Energy Performance: Dealing with Practical Issues of Data Availability and Granularity in a UK School Building. Cambridge, UK, IBPSA England, pp. 503-510.

Kapalo, P., 2013. Analysis of ventilation rate and concentration of carbon dioxide in the office. s.1.:Technical University of Kosice, Slovakia.

Kimpian, J. \& Chisholm, S., 2011. Tracking Design and Actual Energy Use: CarbonBuzz, an RIBA CIBSE platform,. Louvain-la-Neuve, Int. PLEA conference.

Morgenstern, P., Raslan, R. \& Ruyssevelt, P., 2016. Reducing hospital electricity use: an end-use perspective. Frankfurt, 9th IEECB\&SC'16.

NHS Digital, 2018. ERIC.[Online]

Available at: https://digital.nhs.uk/data-andinformation/ publications/statistical/estates-returnsinformation-collection [Accessed 201901 22].

Parsons, P., 2014. Determining Infiltration Rates and Predicting Building Occupancy Using CO2 Concentration Curves. Journal of Energy, Volume 201.

PHE, 2018. Heatwave plan for England: Protecting health and reducing harm from severe heat and heatwaves, London, UK: Public Health England.

Reddy, T. A. \& Maor, I., 2006. Procedures for Reconciling Computer-Calculated Results With Measured Energy Data ASHRAE Research Project 1051- $R P$, Philadelphia: Drexel University.

Sheppy, M., Pless, S. \& Kung, F., 2014. Healthcare Energy End-Use Monitoring, Golden, Colorado: National Renewable Energy Laboratory (NREL).

WHO, 2005. WHO Air quality guidelines for particulate matter, ozone, nitrogen dioxide and sulfur dioxide, Geneva: World Health Organization.

Ziębik, A. \& Hoinka, K., 2013. Energy Systems of Complex Buildings. London: Springer. 
